\title{
Extended-Interval Aminoglycoside Therapy for Adult Patients with Febrile Neutropenia: A Systematic Review
}

\author{
Sarah N Stabler and Mary H H Ensom
}

\begin{abstract}
Background: Although the efficacy and toxicity of extended-interval (once-daily) aminoglycoside regimens is well established for immunocompetent patients, there is clinical concern about using this regimen for patients with neutropenia.
\end{abstract}

Objective: To summarize and evaluate the literature reporting the clinical efficacy and safety of extended-interval aminoglycosides therapy in adults with febrile neutropenia.

Methods: A literature search was conducted within PubMed, Embase, and the Cochrane Database of Systematic Reviews to identify studies assessing the use of extended-interval aminoglycosides for treating febrile neutropenia in adults. Articles were categorized by quality of evidence, according to the rating scale of the US Preventive Services Task Force.

Results: Ten articles were identified: 5 with level I evidence, 1 with level II- 2 evidence, and 4 with level III evidence. Review of the 5 studies with level I evidence (all open-label randomized controlled trials), which compared extended-interval dosing with multiple-daily dosing strategies, revealed no evidence to suggest superiority of one regimen over the other in terms of clinical outcomes. In the study with level II-2 evidence (a prospective comparative trial), the response rate was better in the extendedinterval group than in the standard-therapy group. Two of the studies with level III evidence (both prospective noncomparative trials) also had acceptable response rates to extended-interval aminoglycoside therapy, with minimal associated nephrotoxicity. In this review, no major differences in rates of nephrotoxicity or ototoxicity were seen between the 2 dosing regimens.

Conclusions: The use of extended-interval dosing for aminoglycosides, in combination with other recommended antibiotic therapy, is an effective and safe management strategy for immunocompromised patients with febrile neutropenia. In this population, the clinical efficacy and safety of extended-interval dosing does not appear to differ from those of standard dosing. Whether routine or selective pharmacokinetic monitoring in this patient subpopulation leads to improvements in outcomes is yet to be determined.

Key words: aminoglycosides, extended-interval dosing, febrile neutropenia

\section{RÉSUMÉ}

Contexte : Malgré que l'efficacité et la toxicité des aminosides administrés à intervalle posologique prolongé (une fois par jour) soient bien documentées chez les patients immunocompétents, certains ont des inquiétudes sur le plan clinique quant à l'utilisation de ce schéma thérapeutique chez les patients souffrant de neutropénie.

Objectif : Résumer et évaluer la littérature faisant état de l'efficacité et de l'innocuité cliniques des aminosides administrés à intervalle posologique prolongé chez des adultes souffrant de neutropénie fébrile.

Méthodes: Une recherche bibliographique a été effectuée dans les bases de données PubMed, Embase et Cochrane Database of Systematic Reviews pour recenser les études évaluant le recours à l'administration d'aminosides à intervalle posologique prolongé dans le traitement d'adultes souffrant de neutropénie fébrile. Les articles recensés ont été classés selon la qualité des données, d'après l'échelle de notation du US Preventive Services Task Force.

Résultats : Dix articles ont été recensés : 5 avec des données probantes de niveau I, 1 avec des données probantes de niveau II-2, et 4 avec des données probantes de niveau III. L'analyse des cinq études présentant des données probantes de niveau I (toutes ouvertes et comparatives avec répartition aléatoire), qui ont comparé des stratégies d'administration uniquotidienne à des stratégies d'administration multiquotidienne, n’a révélé aucune donnée suggérant la supériorité d'un schéma posologique sur l'autre en termes de résultats cliniques. Dans l'étude comportant des données probantes de niveau II-2 (prospective et comparative), le taux de réponse était supérieur dans le groupe intervalle posologique prolongé, comparativement au groupe intervalle posologique standard. Deux des études comportant des données probantes de niveau III (toutes deux prospectives, mais non comparatives) ont révélé également des taux de réponse acceptables à l'administration d'aminosides à intervalle posologique prolongé, avec une néphrotosicité associée minimale. Dans cette analyse, aucune différence majeure dans les taux de néphrotoxicité ou d'ototoxicité n'a été observée entre les deux schémas posologiques.

Conclusions : L'administration d'aminosides à intervalle posologique prolongé en association avec d'autres antibiotiques recommandés constitue une stratégie thérapeutique sûre et efficace chez les patients immunodéprimés souffrant de neutropénie fébrile. Dans cette population, l'efficacité et l'innocuité cliniques des aminosides administrés à intervalle posologique prolongé ne semblent pas être différentes de celles des aminosides administrés à intervalle posologique standard. On ignore 
Can J Hosp Pharm 2011;64(3):182-191 toujours si la surveillance pharmacocinétique systématique ou ponctuelle chez cette sous-population de patients entraîne de meilleurs résultats.

Mots clés : aminosides, intervalle posologique prolongé, neutropénie fébrile

[Traduction par l'éditeur]

\section{INTRODUCTION}

$\mathrm{F}_{\mathrm{c}-\mathrm{m}}$ ebrile neutropenia is common among patients receiving cancer chemotherapy. It is associated with an inpatient mortality rate of $5 \%-10 \%$, as well as substantial morbidity and associated health care costs. ${ }^{1}$ Febrile neutropenia is generally defined as a single oral temperature reading above $38.3^{\circ} \mathrm{C}$ or temperature readings above $38^{\circ} \mathrm{C}$ over a 1 -h period, in conjunction with a neutrophil count less than $0.5 \times 10^{\%} / \mathrm{L}$ or less than $1.0 \times 10^{\%} / \mathrm{L}$ and predicted to decline to less than $0.5 \times 10^{9} / \mathrm{L}$ over the next $48 \mathrm{~h} .^{2}$ Prompt administration of antimicrobial therapy is essential; therefore, all patients presenting with fever should undergo an assessment of the risk of infection. ${ }^{2}$

The clinical practice guidelines of the National Comprehensive Cancer Network recommend that patients who meet the criteria for febrile neutropenia receive either single-agent or combination antibiotic therapy active against all suspected organisms (see Table 1). ${ }^{2}$ Aminoglycoside antibiotics are included in these recommendations, but the guidelines do not explicitly endorse use of a specific aminoglycoside dosing regimen. The initial choice of antibiotic therapy should be based on patientspecific factors such as the suspected site of infection, previous colonization with antibiotic-resistant organisms, and recent antibiotic use. Local patterns of antibiotic susceptibility should also be used to guide initial therapy.

Extended-interval aminoglycoside antibiotic dosing takes advantage of the concentration-dependent bactericidal effects

\section{Table 1. Guidelines of the National Comprehensive Cancer Network for Initial Therapy to Treat Fever and Neutropenia ${ }^{2}$}

\begin{tabular}{ll} 
Type of Therapy & Drug Combinations \\
\hline IV monotherapy & Imipenem plus cilastatin \\
& Meropenem \\
& Piperacillin plus tazobactam \\
& Cefepime \\
& Ceftazidime \\
\hline IV combination & Aminoglycoside plus antipseudomonal \\
therapy & penicillin with or without \\
B-lactamase inhibitor \\
Aminoglycoside plus extended- \\
spectrum cephalosporin \\
Ciprofloxacin plus antipseudomonal \\
penicillin
\end{tabular}

of these drugs by producing high peak concentrations and limiting systemic exposure, thereby reducing the potential for toxic effects. ${ }^{3}$ Aminoglycosides also demonstrate a postantibiotic effect, whereby there is continued suppression of bacterial growth after serum levels of the drug drop below the minimum inhibitory concentration. ${ }^{3}$ In theory, the postantibiotic effect allows for continued bactericidal activity during the drug-free intervals that occur with extended-interval dosing of aminoglycosides. In addition, extended-interval dosing takes advantage of the phenomenon of saturable tissue uptake, thereby potentially reducing toxic effects associated with aminoglycoside use. $^{4}$

Although the efficacy and toxicity of extended-interval aminoglycoside regimens is well established for immunocompetent patients, there are clinical concerns about using this regimen for patients with neutropenia. ${ }^{3}$ In particular, there is uncertainty about whether bacterial regrowth may occur during the drug-free interval, because of the lack of neutrophils, leading to worse clinical outcomes and higher infection-related mortality in patients with febrile neutropenia. ${ }^{3}$

Pharmacokinetic monitoring of aminoglycoside concentrations is common in clinical practice. However, the impact of this practice on efficacy and toxicity outcomes in patients with febrile neutropenia has not yet been summarized.

The primary objectives of this systematic review were to summarize and evaluate the literature reporting the clinical efficacy and safety of extended-interval aminoglycosides in adults with febrile neutropenia. Pharmacokinetic assessment of aminoglycosides plays a significant role in monitoring for toxic effects. Therefore, a secondary objective of this review was to summarize the literature describing the pharmacokinetic properties and monitoring of extended-interval aminoglycosides in this subpopulation.

\section{METHODS}

A literature search was conducted within PubMed (1950 to October 2010), Embase (1980 to October 2010), and the Cochrane Database of Systematic Reviews, using the following search terms: "aminoglycoside", "gentamicin", "tobramycin", "amikacin", "netilmicin”, "streptomycin", "neutropenia”, "febrile neutropenia", "once-daily", "multiple daily", "dose administration schedule", and "extended-interval." The objective 
of the search was to identify studies assessing use of extendedinterval aminoglycosides for treatment of febrile neutropenia. The search was limited to English-language articles involving adult human participants. The reference lists of relevant articles identified by these searches were reviewed manually. Studies were excluded if they involved children (under 16 years of age) or if the objective was to evaluate monotherapy or combination therapy that included extended-interval aminoglycosides in patients with febrile neutropenia, without assessing the efficacy, toxicity, or pharmacokinetics of extended-interval aminoglycosides.

Articles were categorized by quality of evidence, according to the rating scale of the US Preventive Services Task Force. ${ }^{5}$ Articles that were not directly relevant to the primary objective of the review but that provided supplemental information regarding the topic of the review (i.e., pharmacokinetic evaluation) were included as "other evidence". The following data elements were extracted from each of the included articles: study design, objective, population, number of patients included, drug regimens used, duration of aminoglycoside therapy, outcome measures, and use of therapeutic drug monitoring.

\section{RESULTS}

One meta-analysis ${ }^{6}$ was identified; however, it was excluded from this review because it included one study that evaluated children and another study that evaluated immunocompromised (but not necessarily neutropenic) patients. In addition, a total of 10 articles $^{7-16}$ were identified through the literature search: 5 with level I evidence, 1 with level II-2 evidence, and 4 with level III evidence. Summaries of the identified articles are presented in Tables 2 and 3.

\section{Level I Evidence}

Level I evidence is defined as evidence from at least one properly conducted randomized controlled trial (RCT).

Five open-label RCTs comparing extended-interval with standard aminoglycoside regimens were identified and were included in this review. All trials used either a cephalosporin or other ß-lactam antibiotics in addition to the aminoglycoside.

The first study included 116 patients with cancer or aplastic anemia with temperature above $38^{\circ} \mathrm{C}$, proven or suspected infection, and neutrophil count below $0.1 \times 10^{\circ} / \mathrm{L}$, with an expectation that it would fall to below $0.05 \times 10^{\%} / \mathrm{L}$. Patients were randomly assigned to receive netilmicin $6 \mathrm{mg} / \mathrm{kg}$ IV every day (extended-interval regimen) or divided every $8 \mathrm{~h}$ (q8h) (standard regimen) with either piperacillin $4 \mathrm{~g}$ IV q8h, azlocillin $5 \mathrm{~g}$ IV q8h, cefotaxime $2 \mathrm{~g}$ IV q8h, or ceftazidime $2 \mathrm{~g}$ IV q8h. The outcomes studied were response to treatment (resolution of fever and any other signs of infection within 14 days of initiation of treatment) and incidence of nephrotoxicity (defined as increase in serum creatinine of more than 50\% above baseline). Patients received a minimum of 5 days of antibiotic therapy (mean duration 8 days, range 3-19 days). There was no significant difference in the percentage of patients with a response to treatment between the standard regimen and the extended-interval regimen (69\% versus $72 \% ; p>0.2)$. There was also no significant difference in nephrotoxicity between the standard-regimen group and the extended-interval group ( $7 \%$ versus $5 \% ; p>0.2)$. Concentrations of netilmicin at peak (measured $30 \mathrm{~min}$ after the end of the infusion) and trough (measured immediately before initiation of the next infusion) were measured twice weekly. Peak concentrations ranged from 4.0 to $36.5 \mathrm{mg} / \mathrm{L}$ in the extended-interval group and from 1.9 to $21.1 \mathrm{mg} / \mathrm{L}$ in the standard-regimen group. Trough concentrations ranged from less than 0.1 to $2.0 \mathrm{mg} / \mathrm{L}$ in the extended-interval group and from less than 0.1 to $4.0 \mathrm{mg} / \mathrm{L}$ in the standard-regimen group.

In an open-label RCT involving 144 patients with a hematologic malignancy, 3 cephalosporin-aminoglycoside regimens were compared: ceftazidime $2 \mathrm{~g}$ IV q8h plus amikacin $7 \mathrm{mg} / \mathrm{kg}$ IV q8h (CFZ), ceftriaxone $2 \mathrm{~g}$ IV q24h plus amikacin $7 \mathrm{mg} / \mathrm{kg}$ IV q8h (CFX-1), and ceftriaxone $2 \mathrm{~g}$ IV q24h plus amikacin $20 \mathrm{mg} / \mathrm{kg}$ IV q24h (CFX-2). ${ }^{8}$ This trial involved patients with temperature above $38^{\circ} \mathrm{C}$ and a neutrophil count less than $0.5 \times 10^{9} / \mathrm{L}$ (or expected to fall below this level within 2 days). The authors examined clinical improvement (lasting return of normal temperature and resolution of signs and symptoms of infection), time to defervesence, death due to infection, nephrotoxicity (not defined), and ototoxicity (not defined). There were no statistically significant differences in the rates of clinical improvement among the 3 groups (Table 3 ). The mean time to defervesence was 5.7 days for the CFZ regimen, 6.3 days for the CFX-1 regimen, and 4 days for the CFX-2 regimen, but no statistical analysis was performed for this outcome. There were 7 deaths $(11 \%)$ due to infection in the CFZ group ( $n=63), 3$ deaths $(10 \%)$ in the CFX-1 group $(n=30)$, and none in the CFX-2 group $(n=51)$, but again, no statistical analysis was performed. Nephrotoxicity and ototoxicity were not observed in any of the patients. The use of monitoring of aminoglycoside serum concentrations was not reported.

An open-label RCT involving 235 patients was conducted to compare extended-interval isepamicin, a semisynthetic aminoglycoside (with pharmacokinetic properties and spectrum similar to those of amikacin), $15 \mathrm{mg} / \mathrm{kg}$ IV q24h with a standard dosing regimen of amikacin $7.5 \mathrm{mg} / \mathrm{kg}$ IV q12h. ${ }^{9}$ Both antibiotics were used in combination with ceftriaxone $2 \mathrm{~g}$ IV q24h. The inclusion criteria for this trial were hematologic malignancy or solid tumour, neutrophil count less than $0.1 \times 10^{\circ} / \mathrm{L}$ and temperature above $38.5^{\circ} \mathrm{C}$ (or above $38^{\circ} \mathrm{C}$ for $3 \mathrm{~h}$ ). The outcomes of interest included treatment success, initial response to treatment but regimen modified, treatment failure, nephrotoxicity (defined as a rise in serum creatinine of more than $0.5 \mathrm{mg} / \mathrm{dL}$ or $44.2 \mu \mathrm{mol} / \mathrm{L}$ ), and ototoxicity (clinical decline in auditory or vestibular inner ear function). No statisti- 
cally significant differences were found between the isepamicin (extended-interval) group and the amikacin (standard) group for all outcomes (see Table 3). ${ }^{9}$ Mortality was also evaluated, but cannot be compared between the groups, because deaths were reported only as combined data from both groups. Peak and trough aminoglycoside concentrations were measured twice weekly. Mean peak serum concentrations \pm standard deviation (for samples drawn $30 \mathrm{~min}$ after the end of the isepamicin infusion) were $57 \pm 37 \mathrm{mg} / \mathrm{L}$ in the isepamicin group and $22 \pm 7 \mathrm{mg} / \mathrm{L}$ in the amikacin group. Mean trough serum concentrations (drawn immediately before the next dose) were $1.3 \pm 2.1 \mathrm{mg} / \mathrm{L}$ in the isepamicin group and 2.7 $\pm 0.7 \mathrm{mg} / \mathrm{L}$ in the amikacin group.

In an open-label RCT involving 92 patients, standard therapy (azlocillin $4 \mathrm{~g}$ IV q6h plus tobramycin $1.5 \mathrm{mg} / \mathrm{kg} \mathrm{q} 8 \mathrm{~h}$ ) was compared with extended-interval therapy (ceftriaxone $2 \mathrm{~g}$ IV q24h plus tobramycin $5 \mathrm{mg} / \mathrm{kg}$ IV q24h). ${ }^{10}$ Flucloxacillin 1-2 g IV q4h could be added if there was clinical suspicion of a staphylococcal infection. Patients included in this trial had an absolute neutrophil count less than $1 \times 10^{9} / \mathrm{L}$ as a consequence of a primary hematologic disorder or chemotherapy for hematologic malignancy, plus any one of the following: temperature above $38^{\circ} \mathrm{C}$ for more than $2 \mathrm{~h}$ or 2 or more temperature spikes above $38^{\circ} \mathrm{C}$ in the absence of an identifiable noninfectious cause of fever, clinically localized site of infection, or clinical diagnosis of septic shock. The outcomes evaluated in this trial were complete response (resolution of fever for 2 sequential days, resolution of local lesions, and recovery from septic shock), death, and nephrotoxicity (not defined). There was no statistically significant difference in complete response to treatment between the standard and extended-interval treatment regimens (see Table 3). Mortality rates were comparable between the 2 groups ( $8.8 \%$ in standard group and $8.5 \%$ in extended-interval group), but no statistical analysis was performed. No patients in either group experienced nephrotoxicity, and monitoring of aminoglycoside serum concentrations was not reported.

The most recent open-label RCT, involving 174 patients, compared tobramycin $6 \mathrm{mg} / \mathrm{kg}$ IV q24h plus penicillin G 5 million IU IV q6h with tobramycin $6 \mathrm{mg} / \mathrm{kg}$ IV divided q8h (first dose doubled) plus penicillin G 5 million IU IV q6h. ${ }^{11}$ Patients with cancer and febrile neutropenia (neutrophil count $\leq 0.5 \times 10^{\circ} / \mathrm{L}$ for $24 \mathrm{~h}$, temperature $\geq 38^{\circ} \mathrm{C}$ ) were randomly assigned to receive either standard ( $\mathrm{q} 8 \mathrm{~h}$ ) or extended-interval aminoglycoside therapy. The outcomes examined in this trial were eradication of infection with no modification of the regimen, time until treatment modification, time to defervesence, change in serum creatinine, and clinically evaluated ototoxicity. No differences were observed between the standard-therapy and extended-interval groups for any of the outcomes evaluated (see Table 3). ${ }^{11}$ No episodes of ototoxicity were noted. No defined pharmacokinetic monitoring protocol was described. However, the mean first peak and trough levels were $16.9 \mathrm{mg} / \mathrm{L}$ (95\% confidence interval [CI] 15.5-18.4 $\mathrm{mg} / \mathrm{L})$ and $0.3 \mathrm{mg} / \mathrm{L}(95 \% \mathrm{CI} 0.2-0.4 \mathrm{mg} / \mathrm{L})$, respectively, in the extended-interval group and $6.4 \mathrm{mg} / \mathrm{L}(95 \%$ CI $6-6.8$ $\mathrm{mg} / \mathrm{L}$ ) and $0.9 \mathrm{mg} / \mathrm{L}(95 \% \mathrm{CI} 0.8-1 \mathrm{mg} / \mathrm{L})$, respectively, in the standard-therapy group. The sampling times were not reported.

Summary: In 5 prospective open-label RCTs, there was no difference in positive treatment outcomes (clinical improvement, success, response, or eradication of infection) between standard dosing ( 2 or 3 times daily) and extended-interval dosing of aminoglycosides in patients with febrile neutropenia. There were no reported increases in the risk of toxic effects with one regimen over another. However, these studies all had small sample sizes (ranging from 92 to 174 patients) and may have been underpowered to show any statistically significant differences. The medication regimens and definitions of outcomes differed across these studies, which makes it difficult to compare their results.

\section{Level II-2 Evidence}

Level II-2 evidence is defined as evidence from welldesigned cohort or case-control analytic studies. The literature search identified one study with this level of evidence.

This prospective comparative trial examined 52 patients with acute myeloid leukemia and febrile neutropenia (neutrophil count $\leq 0.5 \times 10^{\circ} / \mathrm{L}$, temperature $\geq 38^{\circ} \mathrm{C}$, with or without signs of focal infection requiring antibiotic treatment, with or without a positive microbiological result) who were being treated with gentamicin $80 \mathrm{mg}$ IV q8h (standard) or gentamicin $7 \mathrm{mg} / \mathrm{kg}$ IV q24h (extended-interval) with azlocillin $5 \mathrm{~g}$ IV q8h. ${ }^{12}$ Routine monitoring of gentamicin concentration in the serum was performed (exact regimen not reported), and gentamicin doses were adjusted according to peak and trough concentrations (see Table 2). The outcomes examined included response to antibiotic therapy (complete resolution of signs and symptoms of infection for $48 \mathrm{~h}$, regardless of neutrophil count), duration of antibiotic treatment, nephrotoxicity (increase in serum creatinine $>25 \%$ from baseline), and ototoxicity (by audiography and vestibular function testing, but only if symptoms of dizziness or vertigo and signs of balance disturbance were noted). Significantly more patients receiving the extended-interval gentamicin regimen had a response to therapy; however, the required duration of treatment was shorter in the standard-therapy group (see Table 3). There were more cases of nephrotoxicity and ototoxicity in the extended-interval group (no statistical analysis performed); however, there was no difference in overall toxic effects between the groups (see Table 3). ${ }^{12}$ Routine monitoring of gentamicin concentration in the serum was performed, but the monitoring regimen and results were not reported.

Summary: A single prospective comparative trial demonstrated a higher response rate with an extended-interval 


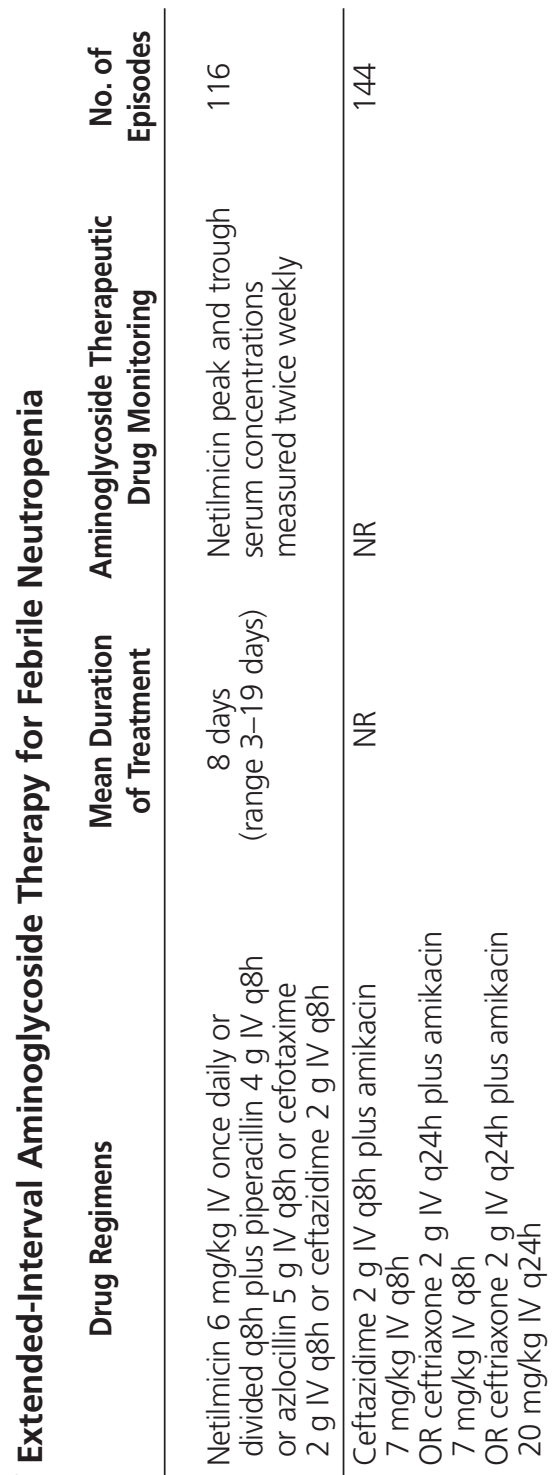

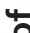

$\frac{3}{\sum_{0}^{2}}$

ह

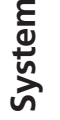

$\stackrel{n}{n}$

$\stackrel{\breve{d}}{\underline{\underline{E}}}$

这

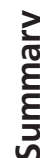

$\frac{5}{5}$
$\sim$
N
$\frac{0}{0}$
$\frac{10}{0}$

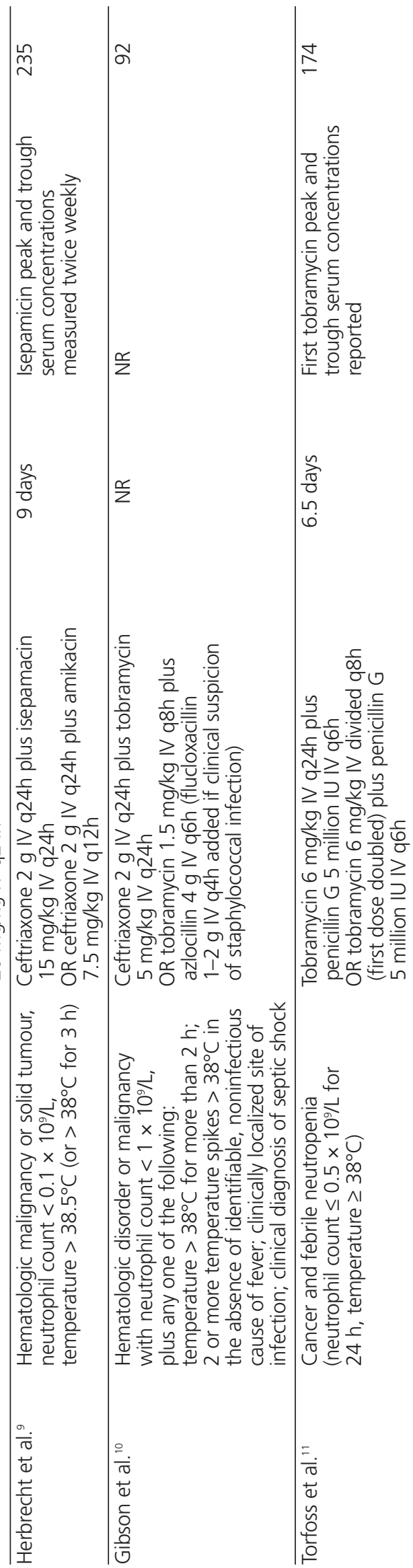

กิ

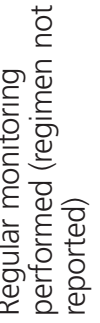

윽츙

은 잉

이의

등

눵 윽

항 음

스

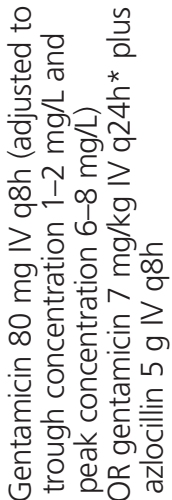

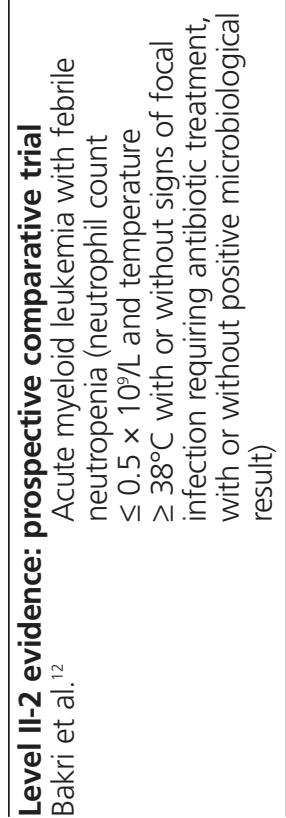




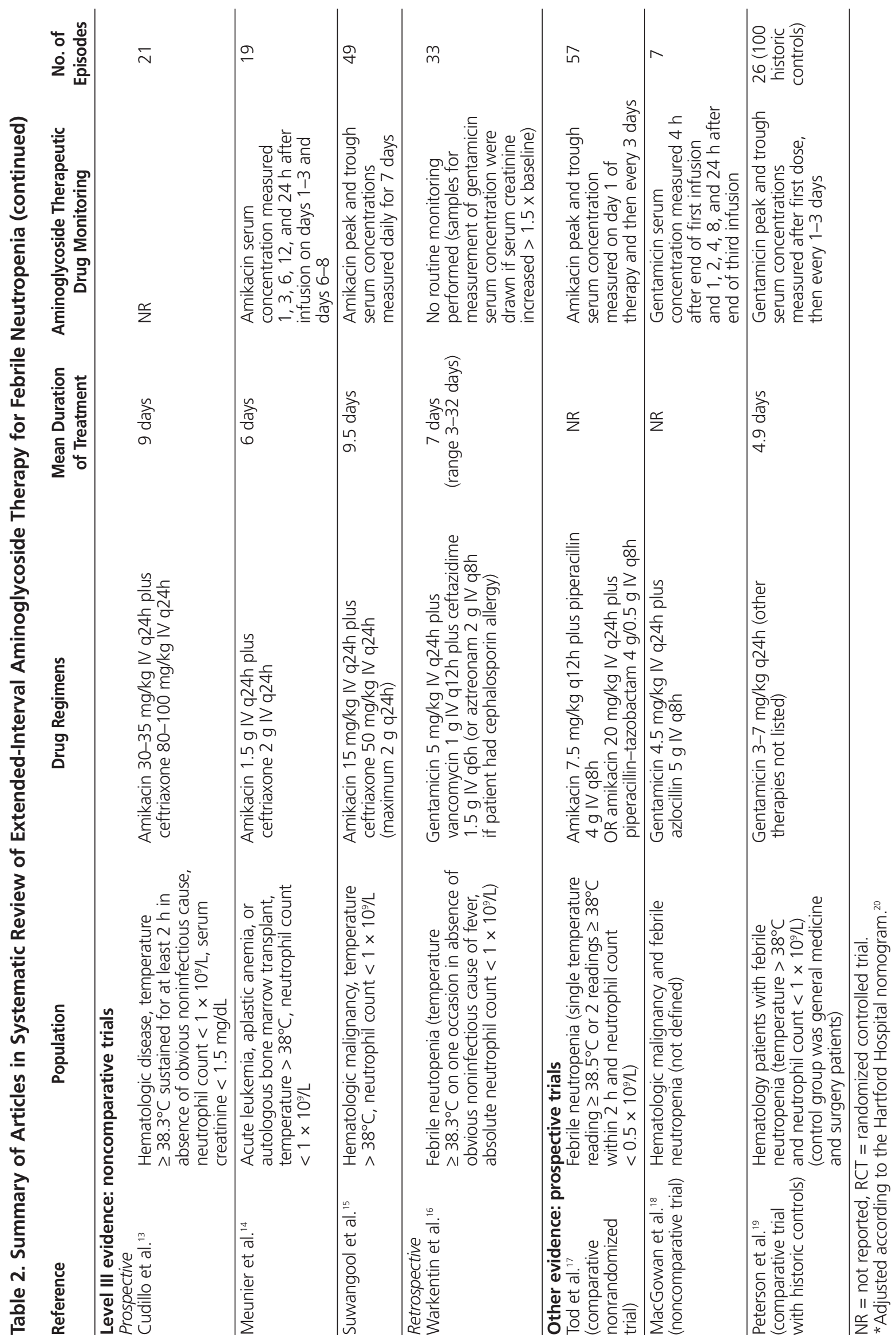




\section{Table 3. Summary of Outcome Measures and Conclusions}

\begin{tabular}{|c|c|c|}
\hline $\begin{array}{l}\text { Level I evidence } \\
\text { Rozdzinski et al. }\end{array}$ & $\begin{array}{l}\text { Controlled trials (open-label) } \\
\text { Comparison: standard therapy v. once-daily administration } \\
\text { Response: } 69 \% \text { v. } 72 \%(p>0.2) \\
\text { Nephrotoxicity: } 7 \% \text { v. } 5 \%(p>0.2)\end{array}$ & $\begin{array}{l}\text { Either } \\
\text { Either }\end{array}$ \\
\hline Leoni et al. ${ }^{8}$ & $\begin{array}{l}\text { Clinical improvement: } 51 \% \text { (CFZ), 80\% (CFX-1), 57\% (CFX-2) (NS) } \\
\text { Time to defervesence: } 5.7 \text { days (CFZ), } 6.3 \text { days (CFX-1), } 4 \text { days (CFX-2) } \\
\text { Death due to infection: } 11 \% \text { (CFZ), 10\% (CFX-1), 0\% (CFX-2) } \\
\text { Nephrotoxicity: None observed } \\
\text { Ototoxicity: None observed }\end{array}$ & Either \\
\hline Herbrecht et al. ${ }^{9}$ & $\begin{array}{l}\text { Comparison: standard thereapy v. once-daily administration } \\
\text { Success: } 29 \% \text { v. } 37 \% \text { (NS) } \\
\text { Initial response, but regimen modified: } 12 \% \text { v. } 13 \% \text { (NS) } \\
\text { Treatment failure: } 59 \% \text { v. } 50 \% \text { (NS) } \\
\text { Nephrotoxicity: } 3.8 \% \text { v. } 4.5 \% \text { (NS) } \\
\text { Ototoxicity: } 1.3 \% \text { v. } 1.9 \% \text { (NS) } \\
\text { Mortality: } 9.4 \% \text { (overall, for both groups combined) }\end{array}$ & Either \\
\hline Gibson et al. ${ }^{10}$ & $\begin{array}{l}\text { Comparison: standard therapy v. once-daily administration } \\
\text { Complete response: } 91 \% \text { v. } 89 \%(p>0.1) \\
\text { Death: } 8.8 \% \text { v. } 8.5 \% \text { ( } p \text { value not reported) } \\
\text { Nephrotoxicity: None observed }\end{array}$ & Either \\
\hline Torfoss et al. ${ }^{11}$ & $\begin{array}{l}\text { Eradication of Infection with no modification of regimen: RR 1.00, } \\
95 \% \mathrm{CI} 0.78-1.27 \\
\text { Time until treatment modification: mean } 5 \text { days (combined), no difference } \\
\text { between groups } \\
\text { Time to defervesence: mean } 59 \mathrm{~h} \text { (range } 8-216 \mathrm{~h} \text { ) (combined), no difference } \\
\text { between groups } \\
\text { Change in serum creatinine level: mean increase of } 0.08 \mathrm{mg} / \mathrm{dL} \\
\text { ( } 95 \% \mathrm{Cl} 0.07-0.10 \mathrm{mg} / \mathrm{dL}), \text { no difference between groups } \\
\text { Ototoxicity: None observed }\end{array}$ & Either \\
\hline
\end{tabular}

Level II-2 evidence: prospective comparative trial

Bakri et al. ${ }^{12}$

Comparison: standard therapy v. once-daily administration

Response to antibiotic therapy: $18.2 \%$ v. $52 \%(p=0.0112)$

Once daily

Duration of antibiotic treatment: 7 days v. 10.4 days $(p=0.026)$

Nephrotoxicity: $3.7 \%$ v. $8 \%$ (p value not reported)

Ototoxicity: $0 \%$ v. $8 \%$ (p value not reported)

Overall toxicity: $3.7 \%$ v. $12 \%(p=0.3409)$

\begin{tabular}{|c|c|}
\hline $\begin{array}{l}\text { Level III evidence } \\
\text { Prospective }\end{array}$ & parative trials \\
\hline Cudillo et al. ${ }^{13}$ & $\begin{array}{l}\text { Treatment success: } 76 \% \\
\text { Nephrotoxicity: None observed } \\
\text { Ototoxicity: None observed }\end{array}$ \\
\hline Meunier et al. ${ }^{14}$ & $\begin{array}{l}\text { Treatment success: } 57.9 \% \\
\text { Nephrotoxicity: } 30.8 \% \\
\text { Ototoxicity: } 42.8 \%\end{array}$ \\
\hline Suwangool et al. ${ }^{15}$ & $\begin{array}{l}\text { Treatment success: 63.3\% } \\
\text { Nephrotoxicity: } 7.1 \%\end{array}$ \\
\hline $\begin{array}{l}\text { Retrospective } \\
\text { Warkentin et al. }{ }^{16}\end{array}$ & $\begin{array}{l}\text { Nephrotoxicity: } 3 \% \\
\text { Ototoxicity: } 12 \%\end{array}$ \\
\hline
\end{tabular}

aminoglycoside regimen than with a standard aminoglycoside regimen. However, the required duration of therapy was significantly shorter with the standard aminoglycoside regimen. Overall, there was no difference in toxic effects between the groups.

\section{Level III Evidence}

Level III evidence is represented by the opinions of respected authorities, based on their clinical experience, by descriptive case reports, or by reports of committees. The literature search yielded a total of 4 studies with this type of evidence. 


\section{Prospective Noncomparative Studies}

Three prospective noncomparative studies reported outcomes associated with the use of extended-interval aminoglycoside therapy in patients with febrile neutropenia.

The first of these studies evaluated 21 patients with hematologic disease, with elevated temperature $\left(\geq 38.3^{\circ} \mathrm{C}\right)$ sustained for at least $2 \mathrm{~h}$ in the absence of an obvious noninfectious cause and a neutrophil count below $1 \times 10^{9} / \mathrm{L}^{13}$ To be included in this study, a patient's serum creatinine had to be less than $1.5 \mathrm{mg} / \mathrm{dL}(132.6 \mu \mathrm{mol} / \mathrm{L})$. Patients were treated with amikacin $30-35 \mathrm{mg} / \mathrm{kg}$ IV q24h plus ceftriaxone $80-100 \mathrm{mg} / \mathrm{kg}$ IV q24h. The mean duration of treatment was 9 days, and 16 patients $(76 \%)$ had treatment success (disappearance of fever and clinical improvement within $72 \mathrm{~h}$ ). There were no reports of nephrotoxicity (method of evaluation not described) or clinically evaluated ototoxicity. Monitoring of aminoglycoside concentration in the serum was not reported.

A second prospective noncomparative study involved 29 patients, of whom 19 had an evaluable episode of febrile neutropenia. ${ }^{14}$ The patients had leukemia or aplastic anemia or had undergone autologous bone marrow transplantation, and all had temperature above $38^{\circ} \mathrm{C}$ and neutrophil count below $1 \times 10^{\%} / \mathrm{L}$. All patients received amikacin $1.5 \mathrm{~g}$ IV q24h plus ceftriaxone $2 \mathrm{~g}$ IV q24h. Overall, 11 of the 19 evaluable episodes were determined to have been successfully treated with empiric extended-interval amikacin and ceftriaxone. Overall, 4 of 13 patients who received amikacin and ceftriaxone (alone, without additional antimicrobial agents) experienced nephrotoxicity, defined as elevation of serum creatinine by at least $20 \%$ over baseline or elevation to $135 \mu \mathrm{mol} / \mathrm{L}$ or higher. Audiometry testing was performed on days 1-3 to assess for ototoxicity. Three (42.8\%) of 7 evaluated patients who received amikacin and ceftriaxone alone met the criteria for ototoxicity (increase of threshold by $15 \mathrm{~dB}$ or more for 2 adjacent frequencies). The mean peak serum concentration of amikacin on days $1-3$ was $60 \mathrm{mg} / \mathrm{L}$, and there was no accumulation of amikacin, as indicated by trough concentrations below $5 \mathrm{mg} / \mathrm{L}$.

The third prospective noncomparative study described 49 cases of febrile neutropenia (temperature $>38^{\circ} \mathrm{C}$, neutrophil count $<1 \times 10^{9} / \mathrm{L}$ ) in patients with various types of hematologic malignancies. ${ }^{15}$ Patients received amikacin $15 \mathrm{mg} / \mathrm{kg}$ IV q24h plus ceftriaxone $50 \mathrm{mg} / \mathrm{kg}$ IV q24h (maximum $2 \mathrm{~g}$ per dose). The mean duration of therapy was 9.5 days. The main outcome of this study was treatment success, achieved by 31 (63.3\%) of the patients. Nephrotoxicity (elevation of serum creatinine by more than $20 \%$ above baseline or to $>1.5 \mathrm{mg} / \mathrm{dL}$ [132.6 $\mu \mathrm{mol} / \mathrm{L}])$ occurred in $3(7.1 \%)$ of 42 patients. The study protocol stated that peak and trough amikacin concentrations were measured daily for 7 days; however, no description or analysis of the measured values was reported.
Summary: Three prospective noncomparative trials demonstrated acceptable response rates to extended-interval aminoglycoside therapy with minimal associated nephrotoxicity.

\section{Retrospective Noncomparative Trial}

One retrospective noncomparative trial was identified, which had the objective of determining risk factors and incidence of toxicity associated with the administration of gentamicin as a single daily dose in patients who had undergone stem cell transplantation. ${ }^{16}$ Thirty-three patients with febrile neutropenia (temperature $\geq 38.3^{\circ} \mathrm{C}$ and neutrophil count $<1 \times 10^{\%} / \mathrm{L}$ ) were treated with gentamicin $5 \mathrm{mg} / \mathrm{kg} \mathrm{IV}$ q24h, vancomycin $1 \mathrm{~g}$ IV q12h, and ceftazidime $1.5 \mathrm{~g}$ IV q6h (with aztreonam $2 \mathrm{~g}$ IV q8h being substituted for ceftazidime in patients with allergy to cephalosporins) for a mean duration of 7 days. One patient experienced a doubling of serum creatinine, which resolved when the therapy was discontinued, and 4 patients experienced clinically evaluated ototoxicity. The mean duration of aminoglycoside therapy was longer for patients with ototoxicity (20 days versus 8.8 days, $p=0.001$ ); however, this was the only identified risk factor that reached statistical significance. The other risk factors assessed were sex, concomitant use of other ototoxic agents, and mean dose of aminoglycoside therapy. The concentration of aminoglycoside in the serum was not measured routinely; samples were drawn for testing only if the patient experienced an increase in serum creatinine of more than 1.5 times above baseline.

Summary: In this retrospective noncomparative trial, patients who experienced ototoxicity while receiving extendedinterval aminoglycoside therapy had a longer mean duration of treatment than those who did not experience this adverse effect.

\section{Other Evidence}

Three additional studies, ${ }^{17-19}$ which focused on the pharmacokinetics of extended-interval aminoglycoside therapy for patients with febrile neutropenia, were identified (Table 2). These studies did not report clinical outcomes and were therefore excluded from the formal analysis.

One of these studies was a prospective nonrandomized trial comparing amikacin $7.5 \mathrm{mg} / \mathrm{kg}$ q12h plus piperacillin $4 \mathrm{~g}$ IV q8h with amikacin $20 \mathrm{mg} / \mathrm{kg}$ IV q24h plus piperacillin-tazobactam $4 \mathrm{~g} / 0.5 \mathrm{~g}$ IV q8h. ${ }^{17}$ The objective was to determine the pharmacokinetic parameters of amikacin administered at extended intervals or twice daily in patients with febrile neutropenia (defined as single temperature reading $\geq 38.5^{\circ} \mathrm{C}$ or 2 readings $\geq 38^{\circ} \mathrm{C}$ within $2 \mathrm{~h}$ and neutrophil count $<0.5 \times 10^{9} / \mathrm{L}$ )] The authors stated that the dosing regimen had no influence on the pharmacokinetic parameters of amikacin and that these parameters were linear over a dosing range of $7.5-20 \mathrm{mg} / \mathrm{kg}$ per day. They also noted that amikacin 
clearance was correlated with creatinine clearance. On the basis of this finding, they recommended that amikacin be dosed as a function of the patient's creatinine clearance.

MacGowan and others ${ }^{18}$ performed a prospective noncomparative trial to examine the pharmacokinetics of gentamicin $4.5 \mathrm{mg} / \mathrm{kg}$ q24h in 7 patients. ${ }^{18}$ Their objective was to determine the optimal times to perform reliable monitoring of serum gentamicin concentration. All included patients had a hematologic malignancy, along with fever and neutropenia, and were treated with gentamicin (dose as stated above) plus azlocillin $5 \mathrm{~g} \mathrm{IV} \mathrm{q8h}$. The results of this study indicated that the distribution phase of gentamicin is not complete until $1-2 \mathrm{~h}$ after a 30-min infusion. On the basis of this kinetic property, the authors recommended that blood samples for gentamicin monitoring be drawn 2-8 $\mathrm{h}$ after the end of the infusion, to yield the most reproducible results.

The third pharmacokinetic study was a prospective trial comparing the pharmacokinetics of extended-interval gentamicin in hematology patients with febrile neutropenia and in general medicine and surgery patients without neutropenia (controls). ${ }^{19}$ All patients received gentamicin 3-7 mg/kg q24h (the exact dose being determined at the discretion of the prescribing physician). There was no difference in gentamicin clearance or volume of distribution between these 2 patient populations.

\section{Therapeutic Drug Monitoring of Aminoglycoside Therapy}

Monitoring of aminoglycoside serum concentrations was reported in 9 of the 13 studies included in this review ${ }^{7,9,1,12,14-18}$ (excluding those with a pharmacokinetic focus). The details of the monitoring regimens used in each trial are described above and summarized in Table 2. Unfortunately, none of these studies analyzed the relationship between serum concentration of aminoglycoside and clinical efficacy or toxicity-related outcomes. Although some of the studies implied that the measurement of aminoglycoside concentration was for the purpose of dose adjustment, only one study ${ }^{12}$ briefly stated the manner in which this dose adjustment was to be performed.

\section{DISCUSSION}

Despite aminoglycoside antibiotics being a mainstay of therapy for the treatment of febrile neutropenia, there is still debate as to the optimal dosing strategy. As mentioned previously, there is uncertainty about whether bacterial regrowth may occur during the drug-free interval (because of a lack of neutrophils), leading to worse clinical outcomes and higher infection-related mortality in patients with febrile neutropenia.

Overall, the studies included in this review had several limitations. Small sample sizes and a lack of blinding may have limited investigators' ability to detect differences in clinical efficacy and toxicity, if they had existed. There was also wide variability in the definitions of febrile neutropenia, treatment success, and toxicity, making it difficult to compare these outcomes across studies. Despite these limitations, the use of extended-interval aminoglycoside therapy for patients with febrile neutropenia appears to be a reasonable management strategy, based on the currently available evidence.

Review of the 5 open-label RCTs comparing extendedinterval with multiple-daily aminoglycoside dosing strategies yielded no evidence to suggest superiority in clinical outcomes of one regimen over the other. ${ }^{7-11}$ One prospective comparative study yielded a significantly better response rate in the extendedinterval group than in the standard-therapy group ${ }^{12}$; however, this study was not blinded or randomized, and the results have not been reproduced.

Nephrotoxicity and ototoxicity are the 2 major adverse effects of concern with the use of aminoglycoside therapy. In this review, no major differences in rates of nephrotoxicity and ototoxicity between the 2 dosing regimens (standard versus extended-interval) were found. ${ }^{7-16}$ As noted above, the mean duration of treatment in a retrospective noncomparative trial was longer for patients who experienced ototoxicity during extended-interval aminoglycoside therapy ${ }^{16}$ Of the 7 studies that assessed patients for ototoxicity, only one provided a description of the method of assessment. ${ }^{14}$ All others stated that ototoxicity was assessed on the basis of clinical evaluation, with no description of the parameters used. ${ }^{8,9,11-13,16}$ Although no increase in rate of ototoxicity was observed with extendedinterval therapy in any of these studies, there remains a need for vigilant monitoring for signs of vestibular damage and auditory changes in patients receiving extended-interval aminoglycoside therapy.

Routine therapeutic monitoring of aminoglycoside levels is commonplace in clinical practice and has the advantage of allowing use of results to tailor therapy to individual patients' pharmacokinetic variations. Although pharmacokinetic monitoring was discussed in several of the trials included in this systematic review, there was no mention of the potential correlation of aminoglycoside levels and/or monitoring with clinical outcomes. The 3 pharmacokinetic studies included in this review suggested that there are no pharmacokinetic concerns of note for aminoglycoside therapy in this patient population. ${ }^{17-19}$ However, there was no suggestion of a desired "therapeutic range", nor were any results provided that would guide routine, or even selective, pharmacokinetic monitoring in this patient population. Furthermore, in those studies in which the sampling protocol was described, the sample for determination of peak level drawn $30 \mathrm{~min}$ after the end of the infusion would provide a falsely elevated peak (or maximum) concentration, as the high-dose aminoglycosides have a prolonged distribution phase. . $7,7,20,21$ Thus, the available evidence regarding pharma- 
cokinetic monitoring in this population provides little insight into population-specific considerations.

Practically speaking, extended-interval administration of aminoglycoside therapy may be a cost-minimizing strategy. ${ }^{22}$ Compared with multiple-daily dosing, extended-interval regimens require fewer resources and personnel and would allow treatment of lower-risk, stable patients in an outpatient setting. For example, at a large (850-bed) hospital, implementation of a hospital-wide policy mandating universal use of extended-interval aminoglycoside therapy resulted in substantial annual cost savings. ${ }^{22}$

\section{CONCLUSIONS}

The available evidence does not suggest superiority, in terms of various efficacy and safety outcomes, of extendedinterval over standard dosing regimens for aminoglycosides used in combination with other recommended antibiotic therapy for patients with febrile neutropenia. Whether routine or selective pharmacokinetic monitoring in this patient subpopulation leads to improvements in outcomes has yet to be determined.

\section{References}

1. Kuderer NM, Dale DC, Crawford J, Cosler LE, Lyman GH. Mortality, morbidity, and cost associated with febrile neutropenia in adult cancer patients. Cancer 2006;106(10):2258-2266.

2. NCCN clinical practice guidelines in oncology: prevention and treatment of cancer-related infections. Version 2.2009. Fort Washington (PA): National Comprehensive Cancer Network; 2009.

3. Aiken SK, Wetzstein GA. Once-daily aminoglycoside in patients with neutropenic fever. Cancer Control 2002;9(5):426-431.

4. De Broe ME, Verbist L, Verpooten GA. Influence of dosage schedule on renal cortical accumulation of amikacin and tobramycin in man. $J$ Antimicrob Chemother 1991;27 Suppl C:41-47.

5. US Preventive Services Task Force. Guide to clinical preventive services: report of the U.S. Preventive Services Task Force. 2nd ed. Baltimore (MD): Williams \& Williams; 1996.

6. Hatala R, Dinh T, Cook DJ. Single daily dosing of aminoglycosides in immunocompromised adults: a systematic review. Clin Infect Dis 1997;24(5):810-815.

7. Rozdzinski E, Kern WV, Reichle A, Moritz T, Schmeiser T, Gaus W, et al. Once-daily versus thrice-daily dosing of netilmicin in combination with ß-lactam antibiotics as empirical theapy for febrile neutropenic patients. J Antimicrob Chemother 1993;31(4):585-598.

8. Leoni F, Ciolli S, Pascarella A, Fanci R, Caporale R, Ferrini P. Ceftriaxone plus conventional or single-daily dose amikacin versus ceftazidime/ amikacin as empiric therapy in febrile neutropenic patients. Chemotherapy 1993;39(2):147-152.

9. Herbrecht R, Blaise D, Espinouse D, Leblond V, Sadoun A, Sauvage C, et al. Isepamicin once daily plus ceftriaxone versus amikacin plus cetriaxone in febrile neutropenic patients. J Chemother 1995;7 Suppl 2:103-110.

10. Gibson J, Johnson L, Snowdon L, Joshua D, Young G, MacLeod C, et al. Single daily ceftriaxone and tobramycin in the empirical management of febrile neutropenic patients: a randomised trial. Int J Hematol 1993;58 (1-2):63-72.

11. Torfoss D, Hoiby EA, Tangen JM, Holte H, Bo K, Meyer P, et al. Tobramycin once versus three times daily, given with penicillin $G$, to febrile neutropenic cancer patients in Norway: a prospective, randomized, multicentre trial. J Antimicrob Chemother 2007;59(4):711-717.
12. Bakri FE, Pallett A, Smith AG, Duncombe AS. Once-daily versus multiple-daily gentamicin in empirical antibiotic therapy of febrile neutropenia following intensive chemotherapy. J Antimicrob Chemother 2000;45(3):383-386.

13. Cudillo L, Masi M, Scimo MT, Tribalto M, Cantonetti M, Criscuolo D, et al. Ceftriaxone plus amikacin in a single daily dose as empiric antibiotic therapy in granulocytopenic patients. J Chemother 1989;1(6):413-416.

14. Meunier F, Van der Auwera P, Aoun M, Ibrahim S, Tulkens PM. Empirical antimicrobial therapy with a single daily dose of ceftriaxone plus amikacin in febrile granulocytopenic patients: a pilot study. J Antimicrob Chemother 1991;27 Suppl C:129-139.

15. Suwangool P, Aswapokee N, Sathapatayavongs B, Leelasuphasri S, Siritanaratkul N, Chuncharunee $S$, et al. Empirical antibiotic therapy in febrile neutropenic patients with single-daily dose amikacin plus ceftriaxone. J Med Assoc Thai 1993;76(6):314-318.

16. Warkentin D, Ippoliti C, Bruton J, Van Besien K, Champlin R. Toxicity of single daily dose gentamicin in stem cell transplantation. Bone Marrow Transplant 1999;24(1):57-61.

17. Tod M, Lortholary O, Seytre D, Semaoun R, Uzzan B, Guillevin L, et al. Population pharmacokinetic study of amikacin administered once or twice daily to febrile, severely neutropenic adults. Antimicrob Agents Chemother 1998;42(4):849-856.

18. MacGowan AP, Bedford KA, Blundell E, Brown NM, Habib F, Hows J, et al. The pharmacokinetics of once daily gentamicin in neutropenic adults with haematological malignancy. J Antimicrob Agents Chemother 1994;34(5):809-812.

19. Peterson AK, Duffall SB. Population analysis of once-daily dosing of gentamicin in patients with neutropenia. Aust N Z J Med 1998;28(3): 311-315.

20. Demczar DJ, Nafziger AN, Bertino JS. Pharmacokinetics of gentamicin at traditional versus high doses: implications for once-daily aminoglycoside dosing. Antimicrob Agents Chemother 1997;41(5):1115-1119.

21. McNamara DR, Nafziger AN, Menhinick AM, Bertino JS. A dose-ranging study of gentamicin pharmacokinetics: implications for extended-interval aminoglycoside therapy. J Clin Pharmacol 2001;41(4):374-377.

22. Nicolau DP, Wu AH, Finocchiaro S, Udeh E, Chow MSS, Quintiliani R, et al. Once-daily aminoglycoside dosing: impact on requests and costs for therapeutic drug monitoring. Ther Drug Monit 1996;18(3):263-266.

Sarah N Stabler, BSc(Pharm), ACPR, PharmD, is a recent graduate of the Doctor of Pharmacy program at the Faculty of Pharmaceutical Sciences, The University of British Columbia, Vancouver, British Columbia. This work was performed while she was a PharmD student.

Mary H H Ensom, PharmD, FASHP, FCCP, FCSHP, FCAHS, is Professor and Director, Doctor of Pharmacy Program, Faculty of Pharmaceutical Sciences, and Distinguished University Scholar, The University of British Columbia, and Clinical Pharmacy Specialist, Department of Pharmacy, Children's and Women's Health Centre of British Columbia, Vancouver, British Columbia. She is also the Editor of the CJHP.

\section{Address correspondence to:}

Dr Mary $\mathrm{H} \mathrm{H}$ Ensom

Department of Pharmacy (OB7)

Children's and Women's Health Centre of British Columbia

4500 Oak Street

Vancouver BC V6B 6E4

e-mail: ensom@mail.ubc.ca 